\title{
Managing Dental Appointments of Insulin-Dependent Diabetic Children
}

\author{
Amjad H Wyne
}

BSc, BDS, MDS, DR MED DENT, FASDC, FADI

Diabetes mellitus (DM) is one of the most common metabolic disorder that affects carbohydrate metabolism. Most dental practices have a number of diabetic patients in the population they serve. Once DM is established in a child, it necessitates maintaining normal blood glucose levels to prevent complications associated with the condition. This paper emphasizes procurement of all necessary medical information before the dental treatment of the child. The paper also discusses necessary precautions that are taken during the dental appointment of an insulin-dependent diabetic child. The possible complications (including hypoglycemic episode in the dental clinic) during dental treatment and their management is also discussed. Most diabetic patients, if cared for appropriately, can be successfully managed as outpatients in the dental clinics. KEYWORDS: Diabetic children, dental management, precautions, complications, peri-operative care.

HOW TO CITE: Wyne AH. Managing dental appointments of insulin-dependent diabetic children. J Pak Dent Assoc 2020;29(3):161-165.

DOI: https://doi.org/10.25301/JPDA.293.161

Received: 26 April 2020, Accepted: 16 May 2020

$\mathrm{D}$ iabetes mellitus (DM) is a metabolic disorder that affects carbohydrate metabolism. ${ }^{1}$ It is characterized by persistent hyperglycemia. ${ }^{2,3}$ It also causes disturbance in lipid and protein metabolism. ${ }^{4-6}$ People without DM have a considerably lower risk of mortality and longer life expectancy as compared to those with DM. ${ }^{7}$ The global DM prevalence was estimated to be $9.3 \%$ in 2019 (463 million people). ${ }^{8}$ The prevalence is estimated to increase to $10.2 \%$ (578 million people) by the year $2030 .{ }^{8}$ The prevalence is lower in rural $(7.2 \%)$ populations than in urban $(10.8 \%)$ ones, and in low-income populations $(4.0 \%)$ than the high-income $(10.4 \%)$ ones. ${ }^{8}$ Pakistan is ranked 4th in the world in the list of countries with the highest DM in adults. ${ }^{9}$ There are approximately half million children under 15 years of age with Type $1 \mathrm{DM}$ worldwide. ${ }^{10}$ According to National Institute of Child Health (NICH) "diabetes is a growing health condition in Pakistani children". ${ }^{9}$ Therefore, it is essential that dental practitioners are aware about how to manage diabetic pediatric dental patients.

\section{TYPES OF DIABETES MELLITUS}

Two major clinical subgroups of DM are; Insulin Dependent DM or Juvenile Diabetes called Type 1; and Non-Insulin Dependent DM more common in adults called Type 2 DM. ${ }^{11}$ Both types of DM patients may use insulin for their glycemic control, however, the Type 1 patients are

Professor and Head, Pediatric Dentistry Department, Institute of Dentistry, CMH Lahore Medical College, Lahore.

Corresponding author: "Prof. Dr Amjad H Wyne" < ahwyne@ gmail.com > truly dependent on insulin for their survival. Due to autoimmune destruction, pancreatic beta cells no longer produces insulin in the Type $1 \mathrm{DM}$ children. Young patients mostly suffer from Type 1 diabetes. ${ }^{12}$ These children present with typical symptoms of polyuria/polydipsia. ${ }^{11}$ About one-third of these children have diabetic ketoacidosis. ${ }^{13}$

\section{MEDICAL CONSIDERATIONS}

Once DM is established in a child, blood glycemic control becomes necessary to prevent complications associated with the disease. Micro-vascular and macro-vascular complications of DM affect multiple organs, resulting in high morbidity and mortality among these patients. ${ }^{14}$ They have an increased risk for coronary artery disease, myocardial infarction and stroke. ${ }^{15}$ These patients are also likely to suffer from blindness, kidney failure, neuropathy, and limb amputation consequent to development of gangrene. ${ }^{15}$ Poor wound healing is also common after surgery on poorly controlled diabetic patients. ${ }^{11}$

Relative or absolute deficiency of insulin and hyperglycemia over long period results in hyperglycemic (diabetic ketoacidotic) coma. This condition takes many hours/days to develop with the following features; too little insulin, infection, myocardial infarction, acute abdominal infection, acidosis causing vomiting, hyperventilation, ketonuria, polyurea, dehydration, hypotension, tachycardia, weak pulse, dry tongue and skin, and abdominal pain. Hypoglycaemic coma on the other hand has a rapid onset that may resemble fainting. It is the result of failure to take food in time, missed meals, over dosage of insulin or other 
hypoglycaemic drugs or extensive exercise. Adrenaline release causes sweaty skin, pounding rapid pulse, anxiety, tremors, dilated pupils, and tingling sensation round the mouth. Cerebral hypoglycemia results in headache, confusion, fits, dysarthria, and unconsciousness. ${ }^{15}$

Daily injection(s) of insulin (especially in type 1 diabetics) and a regulated diet is needed for good glycemic control (Table 1). Diabetic control in children is much more

Table 1: Blood glucose (BG) and HBA1c goals for children and adolescents with Type 1 diabetes. ${ }^{12}$

\begin{tabular}{|c|c|c|}
\hline BG Before Meals & BG Bedtime/Overnight & HBA1c \\
\hline $90-130 \mathrm{mg} / \mathrm{dl}$ & $90-150 \mathrm{mg} / \mathrm{dl}$ & $<7.5 \%$ \\
\hline $5.0-7.2 \mathrm{mmol} / \mathrm{L}$ & $5.0-8.3 \mathrm{mmol} / \mathrm{L}$ & $58 \mathrm{mmol} / \mathrm{mol}$ \\
\hline
\end{tabular}

challenging than in adults because many factors interact to effect the degree of diabetic control in a diabetic child. The insulin dose is also effected by child's growth and development, which makes insulin dose and diet more arduous to control. The physical activity in children is also widely variable that increases challenge of balancing the interaction between insulin intake and dietary regimes. ${ }^{16}$

\section{DENTAL CONSIDERATIONS}

DM children are predisposed to several possible oral problems due to neuropathy, immune dysregulation and vasculopathy in DM children. Their quality of life can be negatively effected due to enhanced risk for periodontal diseases, dental caries, mucosal lesions, salivary glands dysfunction and oral burning. ${ }^{16,17}$ The relationship between DM and periodontal diseases is said to be bi-directional i.e. periodontitis has negative effect on glycemic control and; poor glycemic control tend to worsen the periodontitis in these children. DM children may also have xerostomia (due to salivary gland dysfunction), early tooth eruption, delayed healing of wounds, dysfunction of taste and frequent oral candidiasis. ${ }^{18}$ Diabetic children and their parents/care takers are informed about the possible oral manifestations of DM; and educated on how to prevent any further complications. Meticulous oral hygiene maintenance and a regular dental check-up routine is vitally important in these children.

\section{MANAGEMENT OF THE PATIENT IN DENTAL CLINICS}

The dentist must take a detailed medical history from all the patients/parents, and complete Oral Health Fact Sheet to ensure availability of all the useful facts. ${ }^{18}$ In case one suspects that the child may be diabetic, then the parents and the child are asked about symptoms such as family history of DM, polyuria, polydipsia, polyphagia and weight loss. The suspected child is then referred to a physician for further investigations. In case the child is already an established Type $1 \mathrm{DM}$ patient, the parents and child are asked about medications, their dosages and the time of administration. It is also determined if the child has developed any complications of DM which may effect dental treatment. ${ }^{19}$ The patient's HbA1c (Hemoglobin A1c) test may be ordered. This Hemoglobin A1c test reveals the child's average blood sugar level over the past 2-3 months. The normal HbA1c ranges between $4 \%$ and $5.6 \%$. "If the patient's glycemic control is poor ( $\mathrm{HbA} 1 \mathrm{c}>10 \%)$, elective dental procedures are generally deferred until the glycemic control improves".${ }^{14}$ However, in cases of urgent dental situations, the dentists need to talk to the patients' physician to discuss medicament $\&$ dietary adjustment and discuss possible prophylactic antibiotic coverage. ${ }^{20}$

\section{PRECAUTIONS IN DENTAL TREATMENT}

Most Type 1 DM patients can be provided dental treatment as outpatients in dental clinics. However, those patients who have poor glycemic control (HbA1c>10\%), head and neck infections that are severe, especially those with additional systemic diseases and complications are preferably treated in controlled hospital environment. ${ }^{20}$ Similarly, dental needs that require long-term alteration of medical regimen are considered for treatment under a more controlled medical environment. The DM patients need to bring insulin (pen or with syringe, if required), their blood glucose meter, a glucose source they usually use to avoid a hypoglycemic (hypo) episode and some light snacks at their appointment. ${ }^{20}$ It is also important to ask each patient of his/her signs/symptoms of a hypoglycemic episode onset. This will help the dentist to stop dental treatment immediately in case any of the symptoms develop, and prevent the patient going into deep hypo episode. ${ }^{20}$

These patients should be scheduled for a morning appointment to decrease the risk of hypoglycemia during the dental appointment. In some patients, it may be necessary to modify insulin dose to prevent hypoglycemia especially if there is a possibility of delayed or reduced food intake due to extensive dental treatment. It is important to remember that production of epinephrine and cortisol during stressful situations tend to increase blood glucose levels. ${ }^{21}$ Therefore, pain and stress reduction are vitally important in treating diabetic patients. ${ }^{22}$

It is essential for dentists to confirm that the patient has 
eaten according to his/her normal routine and took the usual medicament. It is important to avoid dental treatment during peak insulin activity to reduce the risk of perioperative hypoglycemic episode..$^{23}$ In case it is not possible to avoid peak insulin activity in patients who take frequent insulin injections, the dentist must take extra precautions such as more frequent monitoring of the patient for perioperative hypoglycemia. The extra precautions include; checking pretreatment blood glucose level using a glucometer and keep carbohydrate source such as a fruit juice or regular soft drink readily available. A small amount of pre-treatment carbohydrate may prevent hypoglycemia if blood glucose level is at the lower end of the normal range (around $80 \mathrm{mg} / \mathrm{dl}){ }^{24}$

A patient may be required not to take breakfast in some situations such as If you plan to use conscious sedation for a stressful procedure or an extensive surgical procedure is planned. In these cases special dietary adjustment and medical consultation becomes necessary. ${ }^{25}$

\section{POSSIBLE COMPLICATIONS DURING DENTAL TREATMENT}

Hypoglycemic episode is the most common complication of diabetes therapy that occurs in dental clinics. A written protocol must exists defining the role of each dental team member in case a diabetes related emergency arises. The patients' blood sugar level drops severely when insulin and/or oral anti-diabetic drug level exceeds patients' physiological needs. Mood changes, hunger, weakness and low spontaneity are initial signs and symptoms, which are followed by tachycardia, sweating, and incoherence. If the condition remains unattended, then possible consequences include hypotension, hypothermia, seizures, coma and death. ${ }^{19}$ Dentist should terminate dental treatment at first sign or symptom of hypoglycemia. The blood glucose level is immediately measured using a glucometer. If a glucometer is not available by any chance, the condition is presumed as a hypoglycemic episode and treated as such. If the patient's blood sugar is more than $60 \mathrm{mg} / \mathrm{dl}$, the patient is given 15 grams of a fast acting oral carbohydrate orally as glucose or 4 - 6 ounces of fruit juice, regular soft drink, or $3-4$ tablespoons of sugar as long as the patient is able to swallow. If the patient is unable to take food by mouth or becoming unconscious, no attempt should be made to give anything through oral route. In such cases, glucagon should be administered intramuscularly or subcutaneously at any body site and, medical emergency services are called. The schedule of pediatric glucagon dose is; $0.02-0.03 \mathrm{mg} / \mathrm{kg}$ or $0.5 \mathrm{mg}$ for patients weighing less than $20 \mathrm{~kg}$, and $1.0 \mathrm{mg}$ for patients weighing $20 \mathrm{~kg}$ or more. ${ }^{18}$ It usually takes $10-15$ minutes for the signs and symptoms of hypoglycemia to resolve. The patient is observed for half an hour to one hour after the recovery. ${ }^{24,26}$ In rare cases, where the patient remains unconscious, the medical emergency services personnel will shift the patient to a hospital.

Severe hyperglycemia takes long time to develop, so risk of hyperglycemic crisis is low in a dental practice. Signs and symptoms of ketoacidosis include nausea, vomiting, abdominal pain and acetone odor. Treatment of hyperglycemia involves administration of insulin and medical intervention. However, to differentiate between hypoglycemia and hyperglycemia based on symptoms alone is difficult. Therefore, it is advisable to administer carbohydrate to such a patient presuming a diagnosis of hypoglycemia. Even if the child is undergoing a hyperglycemic crisis, a small quantity of sugar is unlikely to incur any significant harm to the patient. ${ }^{23}$

\section{RISK OF INFECTIONS}

Dentists should communicate with DM patients' physicians to become familiar with their diabetic status. Poor glycemic control places the child at high risk for infection. Healing ability after surgical procedure is compromised. While it should not prevent the procedure, especially if it is contributing towards poor glycemic control, it has to be carried out with great caution. However, in case of ketosis, the procedure must be postponed until the ketosis is resolved. Antibiotic prophylaxis/coverage is also necessary in such patients and for those undergoing extensive dentoalveolar surgical procedures. Acute orofacial infections require close monitoring and might need adjustment of insulin dosages. ${ }^{26}$

\section{SUMMARY}

Most of the Type 1 Diabetes Mellitus children can be managed as outpatients for their routine dental treatment given that appropriate precautions are taken during the dental treatment. The dentist and the dental clinic staff should be familiar with how to effectively deal with hypoglycemic situation in diabetic children. Diabetic children need frequent dental visits for early detection and intervention of oral infections. However, greater attention and emphasis should be directed toward prevention of oral diseases in these patients.

\section{ACKNOWLEDGEMENT}

The author wishes to thank Dr. Rasha Aldhaban, Associate Professor of Pediatric Dentistry at King Saud 
University College of Dentistry for providing some hard copies of the literature utilized in preparation of this review.

\section{CONFLICT OF INTEREST}

The author does not have any conflict of interest.

\section{DISCLAIMER}

The professional guidelines and standards of care keep changing and continuously updated by various organizations. Readers are strongly encouraged to keep abreast of latest developments in their areas of health care.

\section{REFERENCES}

1. World Health Organization. Diabetes. https://www.who.int/newsroom/fact-sheets/detail/diabetes. Accessed on 31st March 2020.

2. American Diabetes Association. Diagnosis and classification of diabetes mellitus. Diabetes Care. 2009;32 Suppl 1(Suppl 1):S62-S67. https://doi.org/10.2337/dc09-S062

3. Eisenbarth GS, Castano L. Diabetes mellitus. In: Frank MM, Austen KF, Claman HN, et al (eds). Samter's Immunologic Disease. 5th edition. Boston: Little, Brown \& Co, 1995:1007.

4. Ervasti T, Knuuttila M, Pohjamo L, Haukipuro K. Relation between control of diabetes and gingival bleeding. J Periodontol 1985; 56:154157.

https://doi.org/10.1902/jop.1985.56.3.154

5. Becker DJ. Diabetes mellitus and hypoglycemia. In: Lifshitz F (ed). Pediatric Endocrinology. 3rd edition. New York: Marcel Dekker, Inc, 1996:555-66.

6. Nepomuceno R, Vallerini BF, da Silva RL, Corbi SCT, Bastos AS, et al. Systemic expression of genes related to inflammation and lipid metabolism in patients with dyslipidemia, type 2 diabetes mellitus and chronic periodontitis. Diabetes Metab Syndr 2019;13:2715-2722. https://doi.org/10.1016/j.dsx.2019.07.003

7. Gu K, Cowie CC, Harris MI. Mortality in adults with and without diabetes in a national cohort of the U.S. population. Diabetes Care 1998; 21:1138-1145.

https://doi.org/10.2337/diacare.21.7.1138

8. Saeedi P, Petersohn I, Salpea P, Malanda B Karuranga S, et al. Global and regional diabetes prevalence estimates for 2019 and projections for 2030 and 2045: Results from the International Diabetes Federation Diabetes Atlas, 9th edition. Diabetes Res Clin Pract 2019:157:1-10.

https://doi.org/10.1016/j.diabres.2019.107843

9. National Institute of Child Health. Diabetes a growing health condition for children in Pakistan. https://www.thenews.com.pk/latest/6563-diabetes-a-growing-healthcondition-for-children-in-pakistan. Accessed on 13th March 2020.

10. Patterson C, Guariguata L, Dahlquist G, Soltész G, Ogle G, Silink M. Diabetes in the young - a global view and worldwide estimates of numbers of children with type 1 diabetes. Diabetes Res Clin Pract 2014;103:161-75.Epub o0 Dec 2013.

https://doi.org/10.1016/j.diabres.2013.11.005

11. American Diabetes Association. The path to understanding diabetes starts here. https://www.diabetes.org/diabetes. Accessed on 12th March 2020/

12. American Diabetes Association. Children and Adolescents: Standards of Medical Care in Diabetes - 2018. Diabetes Care 2018 Jan; 41(Supplement 1): S126-S136. https://doi.org/10.2337/dc18-S012

13. American Diabetes Association. Classification and Diagnosis of Diabetes: Standards of Medical Care in Diabetes - 2020. Diabetes Care 2020; 43 (Supplement 1): S14-S31.

https://doi.org/10.2337/dc20-S002

14. Chawla A, Chawla R, Jaggi S. Microvasular and macrovascular complications in diabetes mellitus: distinct or continuum?. Indian J Endocrinol Metab. 2016;20:546-51

https://doi.org/10.4103/2230-8210.183480

15. Scully C. Scully's Medical Problems in Dentistry. 7th edition. London:Churchill Livingstone, 2016:256-65.

16. Faulconbridge AR, Bradshaw WCL, Jenkins PA, Baum JD. The dental status of a group of diabetic children. Brit Dent J 1981; 151:25355 .

https://doi.org/10.1038/sj.bdj.4804683

17. Díaz Rosas CY, Cárdenas Vargas E, Castañeda-Delgado JE, Aguilera-Galaviz LA, Aceves Medina MC. Dental, periodontal and salivary conditions in diabetic children associated with metabolic control variables and nutritional plan adherence. Eur J Paediatr Dent 2018;19:119-26.

https://doi.org/10.23804/ejpd.2018.19.02.05.

18. School of Dentistry. University of Washington. Oral Health Fact Sheet for Dental Professionals. Children with Type 1 Diabetes. https://dental.washington.edu/wp-content/media/sp_need_pdfs/ Diabetes-Dental.pdf.

19. Lalla RV, D'Ambrosio JA. Dental management considerations for the patient with diabetes mellitus. J Am Dent Assoc. 2001; 132:1425-432.

https://doi.org/10.14219/jada.archive.2001.0059

20. Wray, L. The diabetic patient and dental treatment: an update. $\mathrm{Br}$ Dent J 2011, 211:209-215. https://doi.org/10.1038/sj.bdj.2011.724

21. Varon F, Mack-Shipman L. The role of the dental professional in diabetes care. J Contemp Dent Pract 2000;15:1-27.

https://doi.org/10.5005/jcdp-1-2-44 


\section{Managing Dental Appointments of Insulin-Dependent Diabetic Children}

22. Reese TD. The diabetic dental patient. Dent Clin North Am 1994; 38:447-463.

23. Mealey BL. Impact of advances in diabetes care on dental treatment of the diabetic patient. Compend Contin Educ Dent 1998; 19:41-58.

24. Mealey B. Diabetes Mellitus. In: Greenberg MS and Glick M (eds). Burket's Oral Medicine, Diagnosis and Treatment. 10th edition. Hamilton: BC Deckers Inc. 2003:563-77.
25. American Academy of Periodontology. Diabetes and Periodontal Diseases. Committee on Research, Science and Therapy. J Periodontol 2000;71:664-78.

https://doi.org/10.1902/jop.2000.71.4.664

26. Nirmala SG, Saikrishna D. Dental Care and Treatment of Children with Diabetes Mellitus- An Overview. J Pediatr Neonatal Care 2016;4:114.

https://doi.org/10.15406/jpnc.2016.04.00134 